\title{
APLIKASI PENCARIAN USTADZ UNTUK WILAYAH KOTA MAKASSAR MENGGUNAKAN ALGORITMA FLOYD WARSHALL DAN HAVERSINE FORMULA BERBASIS ANDROID
}

\author{
Rifaldy Ramadhan Latief ${ }^{1)}$, Andani Achmad ${ }^{2}$, dan Supriadi Sahibu ${ }^{3)}$ \\ ${ }^{1,2,3}$ Program Studi Pascasarjana Sistem Komputer, Stmik Handayani Makassar \\ Jalan Adhyaksa Baru No.1, Pandang, Selatan 90231 \\ E-mail : rifaldyramadhan94@gmail.com ${ }^{1)}$, andani@unhas.ac.id ${ }^{2)}$, \\ supriadi@handayani.ac.id ${ }^{3)}$
}

\begin{abstract}
ABSTRAK
Dakwah adalah kegiatan yang bersifat menyeru, mengajak dan memanggil orang untuk beriman dan taat kepada Allah sesuai garis aqidah, syariat dan akhlak islam. Kegiatan berdakwah sering dilaksanakan oleh umat Islam dalam berbagai kegiatan keislaman yang dilakukan oleh para pendakwah/penceramah. Namun masih sulit untuk menentukan jadwal dan lokasinya. Dikota Makasar sendiri, terdapat banyak Masjid dan lokasi ceramah yang masih minim informasi alamatnya, sehingga penceramah sering kali kesulitan menemukan lokasi ceramah. Tujuan dari penelitian ini adalah untuk memudahkankan masyarakat mencari penceramah dan memudahkan penceramah mencari lokasi ceramah dengan merancang suatu sistem pencarian sebagai media informasi penyedia jasa dakwah untuk masyarakat. Dalam melakukan penelitian ini, jenis penelitian yang digunakan adalah metode penelitian kualitatif dengan menggunakan strategi Design dan creation sebagai konsep yang sangat tepat untuk mengolah penelitian ini. Hasil dari penelitian ini berupa aplikasi mobile dimana masyarakat dapat mencari penceramah dan penceramah dapat menentukan lokasi ceramah dengan lebih mudah. Berdasarkan pernyataan diatas, bahwa ustadz Sangat berperan penting dalam kehidupan sehari-hari. Untuk itu perlu dibuatkan sebuah aplikasi berbasis Android yang dapat membantu masyarakat muslim kota Makassar untuk mencari penceramah disetiap kegiatan keislaman untuk mengisi acara dakwah.
\end{abstract}

Kata kunci : Pencarian, Dakwah, Ustadz, Android

\section{PENDAHULUAN}

Dakwah yang dipersepsikan oleh masyarakat pada umumnya adalah kegiatan penyampaian pesan verbal yang berisi nasehat-nasehat agama beserta dalil-dalil yang dijadikan rujukan. Mereka yang menyampaikan dakwah sering disebut sebagai ustadz, kiyai, ulama, atau mereka yang dinilai sebagai ahli agama (Akhyar, 2014). Di Indonesia, ada berbagai macam cara penceramah menyampaikan isi ceramahnya sesuai bahasa dan dialek daerah tempat ia berceramah. Semakin dekat bahasa yang digunakan dengan bahasa daerah setempat, maka lebih mudah isi dan pesan ceramahnya diterima. Oleh karena itu, terkadang ada beberapa daerah yang hanya memprioritaskan penceramah tertentu untuk berceramah di tempatnya. Di kota Makassar terdapat ratusan masjid dan lokasi ceramah yang masih minim informasi alamatnya sehingga khatib atau penceramah seringkali kesulitan menemukan lokasi yang ditempati khutbah atau ceramah. Kesulitan ini menyebabkan khatib atau penceramah kadang tidak melaksanakan tugasnya di lokasi yang telah dijadwalkan. Alamat atau lokasi menjadi informasi agar khatib dan penceramah dapat menemukan lokasi yang ditempati khutbah atau ceramah. Meskipun pada penelitian terdahulu, sudah dibuat sebuah sistem terintegrasi manajemen penjadwalan khatib pada masjidmasjid yang terdaftar pada lembaga dakwah, akan tetapi sistem tersebut kurang fleksibel. Hal ini dikarenakan, sistem terdahulu hanya dimanfaatkan oleh Lembaga Dakwah dan beberapa masjid yang telah terdaftar. Sehingga, terbatasnya informasi untuk ustadz yang belum terdaftar. Perkembangan teknologi merupakan salah satu bidang ilmu pengetahuan yang berkembang pesat saat ini. Smartphone merupakan telepon genggam yang mempunyai kemampuan tingkat tinggi, bahkan dengan fungsi yang menyerupai komputer. Tentunya banyak sekali fasilitas-fasilitas yang diberikan oleh smartphone sehingga saat ini banyak sekali peminatnya. Jika awalnya pengguna smartphone ini adalah para pejabat atau karyawan swata, wanita karir juga eksekutif muda. Namun saat ini pengguna smartphone sudah meluas ke semua kalangan (Lutfi Parmuarip, 2012). Adapun peenelitian yang dilakukan oleh Hakim pada 2014. Penelitian ini berjudul "Sistem Informasi Penjadwalan Kunjungan Perpustakaan Keliling Berbasis Web dengan SMS Gateway pada Kantor Perpustakaan dan Arsip Daerah Kabupaten Kudus". Tujuan dari tesis ini adalah untuk merancang dan membangun suatu sistem penjadwalan kunjungan perpustakaan keliling beserta pemberian informasi jadwal kunjungan melalui sms guna memudahkan koordinator perpustakaan keliling dalam mengelola jadwal kunjungan perpustakaan keliling beserta informasinya. Konsep yang diterapkan dalam 
tahap perancangan Sistem Penjadwalan Kunjungan Perpustakaan Keliling Berbasis Web dengan SMS Gateway pada Kantor Perpustakaan dan Arsip Daerah Kabupaten Kudus adalah dengan menggunakan Waterfall. Sedangkan bahasa pemrograman yang digunakan adalah PHP. Dengan ilmu pengetahuan, manusia dapat mengetahui benda-benda langit, menjelajahi angkasa raya, dan menembus sekat-sekat yang selama ini belum terkuak. Manusia diberi potensi oleh Allah swt. berupa akal. Akal ini harus terus diasah, diberdayakan dengan cara belajar dan berkarya. Dengan belajar, manusia bisa mendapatkan ilmu dan wawasan yang baru. Dengan ilmu, manusia dapat berkarya untuk kehidupan yang lebih baik.

\section{RUANG LINGKUP}

Adapun focus penelitian tersebut adalah :

1. Mengimplementasikan sebuah aplikasi yang berjalan pada sistem operasi berbasis android minimal versi android 4.4: kitkat.

2. Mengimplementasikan aplikasi pencarian lokasi rumah penceramah dengan memanfaatkan memanfaatkan Global Positioning System (GPS) dan Google Map API.

3. Menerapkan metode Floyd Warshall dan Haversine Formula dalam menentukan jarak terdekat pada aplikasi?

4. Menerapkan radius dalam menampilkan jarak terdekat pada aplikasi?

\section{BAHAN DAN METODE}

Adapun bahan dan metode yang di gunakan dan membangun aplikasi yaitu:

\subsection{Definisi Sistem}

Definisi sistem (Norman, 2004) menyatakan bahwa suatu sistem dapat terdiri atas kegiatan- kegiatan yang berhubungan guna mencapai tujuan- tujuan perusahaan seperti pengendalian inventaris atau penjadwalan produksi. Sedangkan menurut (prajudi, 2004) menyatakan bahwa suatu sistem terdiri atas objek- objek, atau unsurunsur, atau komponen-komponen yang berkaitan atau berhubungan satu sama lainnya sedemikian rupa sehingga unsur-unsur tersebut merupakan satu kesatuan pemprosesan atau pengolahan yang tertentu.

\subsection{Basis Data Berorientasi Objek (Database)}

Menurut Connolly dan Begg (2005, p15), "Basis data adalah sebuah koleksi logical data yang saling terhubung satu sama lain dan gambaran dari data tersebut dirancang untuk menemukan kebutuhan informasi pada suatu organisasi atau perusahaan”. Konsep Objek Oriented Database (OODB) bermula dari Objek Oriented Programming (OOP) yang kemudian dikembangkan menjadi Objek Oriented Design (OOD) dan pada akhirnya menjadi Objek Oriented Analysis (OOA). Didalam konsep objek oriented database kita dapat melakkukan pemodelan data dari semua atributatribut khusus dari iap model dan dapat dinyatakan dalam
Bahasa umum (natural).

OODB pada dasarnya merupakan konsep dari pemrograman berorientasi objek secara umum ditambah dengan database sebagai media penyimpanan datanya yang berbentuk class-class, sehingga dalam hal ini masih berhubungan erat dengan Diagram ER (Entity Relational Diagram), walau sudah mengalami perubahan bentuk dalam memodelkan objek-objeknya. OODB masih menerapkan konsep dari Relational Database Manajemen Sistem (RDBMS). Mekanisme penyimpanan obje-objek dalam RDBMS ini Sering dikenal dengan istilah ORDBMS (Objek Relational Database Management System).

\subsection{Metode Waterfall}

Menurut (Rosa, 2011) model SDLC air terjun (waterfall) sering juga disebut model sekuensial liner atau alur hidup klasik. Model air terjun menyediakan pendekatan alur hidup perangkat lunak secara sekuensial atau terurut didalam dari analis, desain, pengodean, pengujian dan tahapan pendukung.

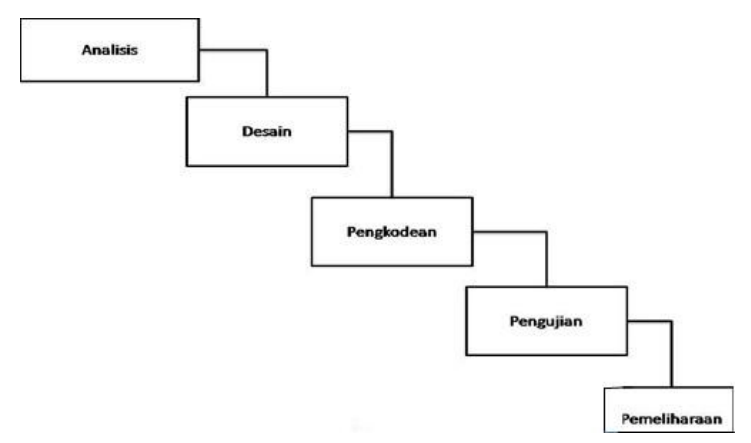

Gambar 1. Model Waterfall

1. Analisa kebutuhan perangkat lunak

Proses pengumpulan kebutuhan dilakukan secara intensif untuk menspesifikasikan kebutuhan perangkat lunak agar dapat dipahami perangkat lunak seperti apa yang dibutuhkan oleh user. Spesifikasi kebutuhan perangkat lunak pada tahap ini perlu untuk didokumentasikan.

2. Desain

Desain perangkat lunak adalah proses multi langkah yang focus pada desain pembuatan program perangkat lunak termasuk struktur data, arsitektur perangkat lunak, representasi antarmukam, dan prosedur pengodean. Tahap ini mentranslasi kebutuhan perangkat lunak dari tahap analis kebutuhan ke representasi desain agar dapat diimplementasikan menjadi program pada tahap selanjutnya. Desain perangkat lunak yang dihasilkan pada tahap ini juga perlu didokumentasikan.

3. Pembuatan Kode Program

Desain harus ditranslasikan ke dalam program perangkat lunak. Hasil dari tahapan ini adalah program komputer sesuai dengan desain yang telah dibuat pada tahapan desain.

4. Pengujian

Pengujian fokus pada perangkat lunak secara dari segi lojik dan fungsional dan memastikan bahwa semua 
bagian sudah diuji. Hal ini dilakukan untuk meminimalisir kesalahan (error) dan memastikan keluaran yang dihasilkan sesuai dengan yang diinginkan.

5. Pendukung (support) atau pemeliharaan (maintenance)

Tidak menutup kemungkinan sebuah perangkat lunak mengalami perubahan ketika sudah dikirimkan ke user. Perubahan bias terjadi karena adanya kesalahan yang muncul dan tidak terdeteksi saat pengujian atau perangkat lunak harus beradaptasi dengan lingkungan baru. Tahap pendukung atau pemeliharaan dapat mengurangi proses pengembangan mulai dari analis spesifikasi untuk perubahan perangkat lunak yang sudah ada, tapi tidak untuk membuat perangkat lunak baru.

\subsection{PHP 5 (Hypertext Preprocessor)}

PHP versi 5 muncul untuk menangani kelemahankelmahan yang terdapat pada versi sebelumnya sampai buku ini ditulis, sudah dikeluarkan PHP 5.0.1 yang juga disertakan dalam CD. PHP versi 5 dapat membuat file swf dan applet java. Secara resmi, PHP versi 5 diluncurkan pada Desember 2003. Fokus utamanya adlah mengoptimalkan penggunaan PHP untuk OOP(Objeck Orientid Program).

PHP menurut (M. Rudyanti, 2011), PHP (Hypertext Prepocessor) adalah bahasa server-side scriping yang menyatu dengan HTML untuk membuat halaman web yang dinamis. Karena PHP merupakan server-side scriping maka sintaks dan perintah-perintah PHP akan dieksekusi di sarver kemudian hasilnya dikirimkan ke browser dalam format HTML. Dengan demikian kode program yang ditulis dalam PHP tidak akan terlihat oleh user sehingga keamanan halaman web yang dinamis, yaitu halaman web yang dapat membentuk suatu tampilan berdasarkan permintaan terkini, seperti penampilan isi basis data ke halaman web.

\subsection{Android}

Android adalah sebuah kumpulan perangkat lunak untuk perangkat mobile yang mencakup sistem operasi, middleware dan aplikasi utama mobile. Telepon seluler menggunakan berbagai macam sistem operasi seperti Symbian OS ${ }^{\circledR}$, Microsoft's Windows Mobile ${ }^{\circledR}$, Mobile Linux ${ }^{\circledR}$, iPhone OS ${ }^{\circledR}$ (berdasarkan Mac OS X), Moblin ${ }^{\circledR}$ (dari Intel), dan berbagai macam sistem operasi lainnya. API yang tersedia untuk mengembangkan aplikasi mobile terbatas dan oleh karena itulah Google mulai mengembangkan dirinya. Platform Android menjanjikan keterbukaan, kemudahan untuk menjangkau, source code yang terbuka, dan pengembangan framework yang high end.

\subsection{Haversine Formula}

Haversine formula merupakan sebuah persamaan yang penting dalam navigasi, dimana formula ini memberikan jarak di antara dua titik pada lingkaran bola dari setiap garis bujur (longitude) dan garis lintang (latitude). Ini adalah kasus khusus dari sebuah formula yang lebih umum dalam trigonometri lingkaran bola, law of haversines, haversine formula menghubungkan sisi dan sudut dari sebuah segitiga bola dalam Haversine formula nantinya akan digunakan perhitungan jarak antara dua titik. Dalam hal ini adalah titik posisi user dan titik posisi tujuan, sehingga dapat menjadi kunci utama dalam perbandingan jarak pada penentuan jarak terdekat.

\section{PEMBAHASAN}

Pada bab ini menerangkan tentang Implementasi Sistem yaitu merupakan pengaplikasian perangkat lunak dan perangkat keras serta database yang digunakan. Tahapan ini dilakukan setelah perancangan selesai dilakukan dan selanjutnya diimplementasi pada bahasa pemrograman, meliputi implementasi Aplikasi yang di buat, batasan implementasi, implementasi perangkat lunak, implementasi perangkat keras, implementasi antar muka, dan implementasi database.

\subsection{Implementasi}

Implementasi atau tahap penerapan ini adalah suatu bentuk kegiatan yang merupakan rangkaian lanjutan dari kegiatan perancangan perangkat lunak, implementasi ini dimaksudkan untuk mewujudkan hasil dari perancangan perangkat lunak. Hasil ini merupakan hasil dari kegiatan rangkaian implementasi perancangan perangkat lunak adalah proses aplikasi yang telah dibuat dan sudah dapat digunakan serta berfungsi dengan baik. Pada umumnya implementasi adalah proses penerapan rancangan program yang telah dibuat pada bab sebelumnya atau aplikasi dalam melaksanakan perancangan aplikasi pemrograman yang dibuat.

\subsection{Implementas Basis Data}

Tampilan Database Pencarian terlihat pada gambar 3, Disini terdapat tabel administrator, kota, ustadz.

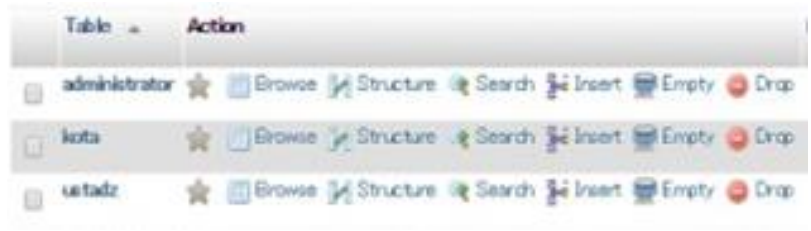

Gambar 2. Struktur database

\subsection{Implementasi dan Pengujian Program}

Berikut ini adalah implementasi dan pengujian program sesuai dengan rancangan layar yang telah dibuat sebelumnya, anatara lain : 
1. Tampilan Login Admin \& Ustadz

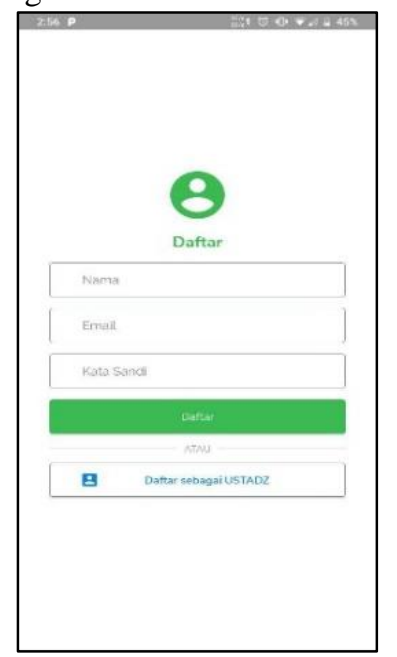

\section{Gambar 3. Tampilan Login Admin}

Ini adalah tampilan login admin sebelum memasuki halaman admin atau ustadz/ustadzah. Disini terdapat username dan password, disini admin atau ustadz/ustadzah diminta memasukan username dan password agar dapat memasuki menu admin.

\section{Tampilan Menu Pencarian Ustadz/Ustadzah}

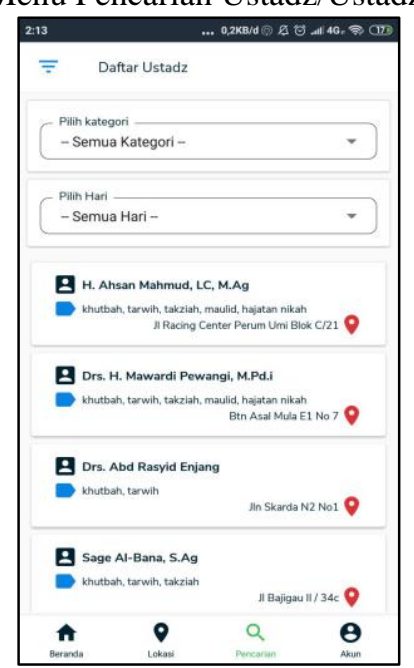

\section{Gambar 4. Tampilan Menu Pencarian Ustadz}

Ini adalah tampilan halaman pencarian ustadz/ustadzah, user bisa langsung mencari ustadz/ustadzah yang terdekat dari user, akan tertera nama ustadz/ustadzah yang terdekat dari user, tidak hanya yang terdekat, user pun bisa mencari ustadz/ustadzah berdasarkan nama atau kota, user hanya ketikan nama kota ataua nama ustadz/ustadzah kemudian klik cari, dengan otomatis sistem akan menampilkannya
3. Tampilan Menu Kelola Ustadz/Ustadzah

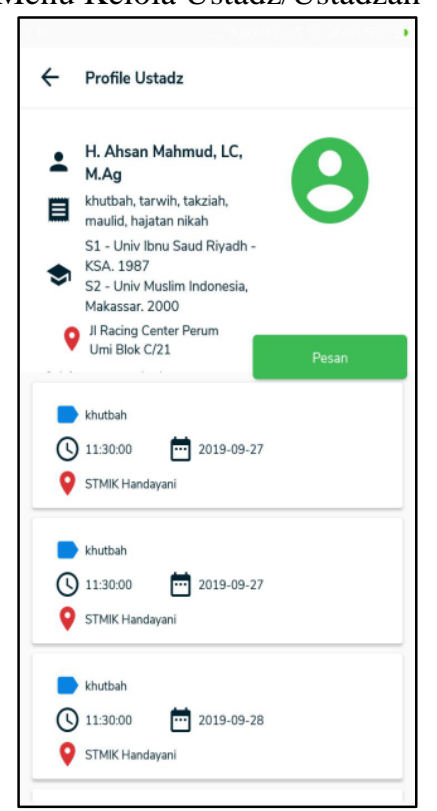

Gambar 5. Tampilan Menu Kelola Ustadz

Ini merupakan tampilan dari menu kelola ustadz/ustadzah. Disini admin dapat mengelola data ustadz/ustadzah seperti, menambahkan ustadz/ustadzah, mengubah data ustadz/ustadzah dan menghapus data ustadz/ustadzah.

\subsection{Metode Pengujian}

Metode pengujian dilakukan untuk memastikan apakah sistem yang akan dipakai sudah sesuai dengan yang diharapkan. Metode yang digunakan untuk pengujian ini adalah black box, yaitu melakukan pengujian degan memfokuskan pada fungsionality sistem tanpa mengetahui apa sesungguhnya yang terjadi dalam black end system.

\section{Prosedur Pengujian}

Pengujian yang digunakan adalah pengujian black box (black-box testing), black box testing terfokus pada apakah unit program memenuhi kebutuhan atau requirement yang disebutkan dalam spesifikasi. Pada black box testing cara pengujian hanya dilakukan dengan menjalankan atau mengeksekusi unit atau modul, kemudian diperhatikan apakah hasil dari unit atau modul itu sesuai dengan proses bisnis yang diinginkan. Pengujuan dengan menggunakan metode black box testing dilakukan dengan cera memberikan sejumlah masukan pada program aplikasi yang kemudian diproses sesuai dengan kebutuhan fungsional nya untuk melihat apakah program aplikasi menghasilkan keluaran yang sesuai dengan kebutuhan fungsionalnya, makan program aplikasi yang dirancang berhasil tetapi bila output yang dihasilkan tidak sesuai dengan kebutuhan fungsionalnya, maka masih terdapat kesalahan pada program aplikasi itu.

Pengujian dilakukan dengan mencoba semua kemungkinan yang terjadi dan dilakukan secara berulang- 
ulang. Jika dalam pengujian ditemukan kesalahan, makan akan dilakukan pencarian dan perbaikan untuk memperbaiki kesalah yang terjadi. Jika telah selesai melakukan perbaikan makan akan dilakukan pengujian kembali. Pengujian dan perbaikan dilakukan secara terus menerus hingga diproleh hasil yang sesuai.

\section{Skenario Pengujian}

Skenario pengujian diperlukan untuk mengetahui apakah aplikasi yang dibuat dapat berfungsi dengan baik atau tidak. Skenario pengujian dilakukan dengan memilih dari setiap pilihan yang ada pada aplikasi e-voting berbasis web dan sms gateway ini, kemudian dilakukan pengujian dengan menekan tombol-tombol yang terdapat pada halaman form dari aplikasi ini apakah sudah sesuai dengan yang diharapkan

Table 1 Rencana Pengujian Halaman Login Admin

\begin{tabular}{|c|c|c|l|}
\hline \multicolumn{4}{|c|}{ Kasus dan Hasil Uji (Data Benar) } \\
\hline $\begin{array}{c}\text { Data } \\
\text { Masukan }\end{array}$ & $\begin{array}{c}\text { Yang } \\
\text { Diharapkan }\end{array}$ & Pengamatan & Kesimpulan \\
\hline Memasukkan & Login data & berhasil & {$[\sqrt{ }]$} \\
ID User/ & & Login & Diterima \\
Ustadz dan & & & {$[$ ] } \\
Password & & & Ditolak \\
\hline
\end{tabular}

\section{Kasus dan Hasil Pengujian}

Berikut adalah beberapa hasil pengujian yang telah dilakukan, yaitu:

1) Pengujian Menu Daftar User

Table 2 Pengujian Menu Daftar User

\begin{tabular}{|c|c|c|l|}
\hline \multicolumn{4}{|c|}{ Kasus dan Hasil Uji (Data Benar) } \\
\hline $\begin{array}{c}\text { Data } \\
\text { Masukan }\end{array}$ & $\begin{array}{c}\text { Yang } \\
\text { Diharapkan }\end{array}$ & Pengamatan & Kesimpulan \\
\hline $\begin{array}{c}\text { Menginput } \\
\text { data user }\end{array}$ & $\begin{array}{c}\text { Menyimpan } \\
\text { data user } \\
\text { berdasarkan } \\
\text { Inputan }\end{array}$ & $\begin{array}{c}\text { Data } \\
\text { berhasil } \\
\text { disimpan }\end{array}$ & $\begin{array}{l}{[\sqrt{ }]} \\
\text { Diterima } \\
{[\text { ] }}\end{array}$ \\
& & Ditolak \\
\hline
\end{tabular}

2) Pengujian Menu User

Table 3 Pengujian Menu User Kasus dan Hasil Uji (Data Normal)

\begin{tabular}{|c|c|c|l|}
\hline \multicolumn{4}{|c|}{ Kasus dan Hasil Uji (Data Benar) } \\
\hline $\begin{array}{c}\text { Data } \\
\text { Masukan }\end{array}$ & $\begin{array}{c}\text { Yang } \\
\text { Diharapkan }\end{array}$ & Pengamatan & Kesimpulan \\
\hline $\begin{array}{c}\text { Menginput } \\
\text { data user }\end{array}$ & $\begin{array}{c}\text { Menyimpan } \\
\text { data user } \\
\text { berdasarkan } \\
\text { Inputan }\end{array}$ & $\begin{array}{c}\text { Data } \\
\text { berhasil } \\
\text { disimpan }\end{array}$ & $\begin{array}{l}{[\sqrt{ }]} \\
\text { Diterima } \\
{[\text { ] }}\end{array}$ \\
& & Ditolak \\
\hline
\end{tabular}

3) Pengujian Menu Lokasi

Table 4 Pengujian Menu Lokasi Kasus dan Hasil Uji (Data Normal)

\begin{tabular}{|c|c|c|l|}
\hline \multicolumn{4}{|c|}{ Kasus dan Hasul Uji (Data Benar) } \\
\hline $\begin{array}{c}\text { Data } \\
\text { Masukan }\end{array}$ & $\begin{array}{c}\text { Yang } \\
\text { Diharapkan }\end{array}$ & Pengamatan & Kesimpulan \\
\hline $\begin{array}{c}\text { Memilih } \\
\text { Lokasi }\end{array}$ & $\begin{array}{c}\text { Menampilkan } \\
\text { Lokasi }\end{array}$ & Lokasi & {$[\sqrt{ }]$} \\
berhasil & Diterima \\
penceramah & penceramah & ditampilkan & {$[$ ] } \\
& & & Ditolak \\
\hline
\end{tabular}

4) Pengujian Menu Pencarian

Table 5 Pengujian Menu Pencarian Kasus dan Hasil Uji (Data Normal)

\begin{tabular}{|c|c|c|l|}
\hline \multicolumn{4}{|c|}{ Kasus dan Hasul Uji (Data Benar) } \\
\hline $\begin{array}{c}\text { Data } \\
\text { Masukan }\end{array}$ & $\begin{array}{c}\text { Yang } \\
\text { Diharapkan }\end{array}$ & Pengamatan & Kesimpulan \\
\hline $\begin{array}{c}\text { Memasukkan } \\
\text { Inputan }\end{array}$ & $\begin{array}{c}\text { Menampilkan } \\
\text { daftar nama } \\
\text { penceramah }\end{array}$ & $\begin{array}{c}\text { Daftar nama } \\
\text { penceramah } \\
\text { berhasil } \\
\text { ditampilkan }\end{array}$ & $\begin{array}{l}{[\sqrt{ }]} \\
\text { Diterima } \\
{[]}\end{array}$ \\
$\begin{array}{c}\text { Ditolak } \\
\text { Kemilih }\end{array}$ & Menampilkan & $\begin{array}{c}\text { List } \\
\text { kategori } \\
\text { Berhasil }\end{array}$ & $\begin{array}{l}{[\sqrt{ }]} \\
\text { Diterima } \\
[]]\end{array}$ \\
& List Kategori \\
& & Ditampilkan & Ditolak \\
\hline
\end{tabular}

\subsection{Analisa Hasil Pengujian}

Setelah dilakukan pengujian secara menyeluruh. Maka dapat disimpulkan bahwa pengujian telah menunjukkan hasil keluaran (Output) dan proses yang sesuai dengan rancangan aplikasi program ini. Dan hasil dari pengujian ini dapat dikatakan bahwa program ini dapat berfungsi dengan baik dan benar, karena telah dibuktikan dari hasil skenario pengujian. Hasil pengujian yang diperoleh dapat dianalisis sebagai berikut:

1. Halaman login, yang mengontrol aktifitas sub menu / link-link dalam sistem.

2. Halaman utama yang menghubungkan antar interface yang terdapat dalam menu berjalan dengan baik.

3. Menu form yang tersedia, hasil inputannya berhasil tersimpan kedalam database dengan tepat.

4. Menu Master, dan Laporan. Setiap tombol menu yang terdapat dimenu tersebut dapat berjalan sesuai perancangan sistem tersebut.

5. Hasil keluaran atau output dapat tercetak sesuai perancangan sistem yang diinginkan. 


\section{KESIMPULAN}

Sistem Pencarian Penceramah ini dibuat berdasarkan kebutuhan masyarakat Makassar untuk mempermudah pencarian penceramah berdasarkan jadwal dan lokasinya. Sistem ini digunakan dua arah langsung oleh penceramah/ustadz dan yang mencari ustadz. Dimana pencari menggunakan sistem untuk mencari penceramah dan sistem mengarahkan kepada ustadz yang sesuai dengan kebutuhan pencari berdasarkan nama, alamat, kategori dan jadwal penceramah tersebut. Kemudian mengisi permintaan jadwal untuk di konfirmasi kepada ustadz. Sistem ini berjalan di sistem operasi Android.

\section{SARAN}

Diharapkan kedepannya untuk keperluan pengembangan sistem, kiranya bisa di perhatikan lagi penambahan beberapa fitur untuk memaksimalkan manfaat aplikasi, diantaranya: aplikasi ini dapat mengakses sampai luar wilayah Makassar bahkan bisa keseluruh dunia, aplikasi ini dapat berkembang, tidak hanya mencari alamat rumah ustadz/ustadzah tetapi langsung mencari keberadaan ustadz/ustadzahnya.

\section{DAFTAR PUSTAKA}

Rosa, dan M. Shalahuddin. Modul Pembelajaran Rekayasa Perangkat Lunak (Terstruktur dan Berorientasi Objek). Bandung: Modula, 2011.
M. Rudyanti Arief, 2004. Pemograman Web Dinamis Menggunakan PHP dan MySQL. Yogyakarta. Penerbit: Andi.

Norman L, Enger, 2004. Analisa Sistem Informasi. Yogyakarta. Penerbit: Andi.

Prajudi Atmosudirdjo, 2004. Administrasi dan Management Umum. Jakarta penerbit : Ghalia Indonesia.

Rosa A.S-M Salahudin, 2011. Modul Pembelajaran Rekayasa Perangkat Lunak (Terstruktur Dan Berorientasi Objek). Bandung Penerbit: Modula

Connolly, Thomas M., Carolyn E. Begg. 2005. Database Systems : A practical approach to design, implamentation, and management, fourth edition. USA : Pearson EducationLimited

Akhyar, "Dakwah Dan Perubahan Sosial". Jurnal. Surabaya, 2014.

Hakim, Luqman. "Sistem Informasi Penjadwalan Kunjungan Perpustakaan Keliling Berbasis Web dengan SMS Gateway pada Kantor Perpustakaan dan Arsip Daerah Kabupaten Kudus". Tesis. Kudus: Fakultas Teknik Universitas Muria. 2014.

Lutfi Parmuarip, Wildan Muslim, Yeni Mulyani, “Alasan Penggunaan Smartphone di Kalangan Mahasiswa Politeknik Negeri Bandung”. Tesis. Bandung: Jurusan Teknik Komputer dan Informatika Politeknik Negeri Bandung. 2012 